\title{
A Vietnamese version of the 14-item oral health impact profile (OHIP-14VN)
}

\author{
Anneloes E. Gerritsen ${ }^{1 *}$, Thoa C. Nguyen ${ }^{2}$, Dick J. Witter ${ }^{1}$, Ewald M. Bronkhorst ${ }^{3}$, \\ Nico H. J. Creugers ${ }^{1}$ \\ ${ }^{1}$ Department of Oral Function and Prosthetic Dentistry, College of Dental Science, Radboud University Nijmegen Medical Centre, \\ Nijmegen, The Netherlands \\ ${ }^{2}$ Department of Prosthodontics, Faculty of Dentistry, Cantho University of Medicine and Pharmacy, Cantho, Vietnam \\ ${ }^{3}$ Department of Community and Restorative Dentistry, College of Dental Science, Radboud University Nijmegen Medical Centre, \\ Nijmegen, The Netherlands \\ Email: " a.gerritsen@,dent.umcn.nl
}

Received 9 November 2011; revised 14 December 2011; accepted 28 December 2011

\section{ABSTRACT}

Aim: To validate a Vietnamese short version (OHIP$14 V N)$ for use in epidemiological studies. Methods: The original English-language version was translated into Vietnamese, back translated and after some revisions tested for psychometric properties. Subjects $(\mathrm{n}=$ 724) were asked to self-administer a questionnaire but could ask for assistance. Convergent validity was tested by investigating associations between OHIP domain and total scores, and dichotomized self-reported satisfaction with 1) the dentition in general, 2) chewing function, and 3) esthetics. Groups validity was evaluated by comparing OHIP scores of subjects having $\leq 6$ molars vs. $>6$ molars and tooth decay vs. no decay. Test-retest reliability was investigated in a convenience sample $(n=54)$ and expressed in Intraclass Correlation Coefficients (ICCs). Internal consistency was assessed by Cronbach's alpha and average inter-item correlation coefficients. Results: Validity: all associations were in the hypothesized directions. Differences in mean OHIP total were statistically significant for all discriminative variables. OHIP scores completed with assistance were significantly lower than those from self-administered questionnaires and therefore analyzed separately. For both administration formats differences in mean scores were still significant for "satisfaction" but for having $\leq \mathbf{6}$ molars or decay the differences lost significance for most domain and total scores. Reliability: ICCs ranged from 0.54 - 0.74. Internal consistency: Cronbach's alphas for OHIP total scores were 0.93 (self-administered) and 0.91 (with assistance). Average inter-item correlation coefficients ranged from $0.26-0.67$ (self-administered) and $0.28-0.69$ (with assistance). Conclusions: This Vietnamese version of the OHIP-14 dem-

\footnotetext{
"Corresponding author.
}

onstrated good construct validity and acceptable reliability for OHIP total scores however OHIP-14VN domain scores should be interpreted with caution.

Keywords: Oral Health Impact Profile; OHIP-14; Vietnamese Version; Validation; Administration Format

\section{BACKGROUND}

It has been recognized that not only objective indicators are important when evaluating oral diseases or treatment outcomes [1,2]. Therefore, since the nineties of the previous century, studies also focus on patients' perception, for example by assessing oral health-related quality of life (OHRQoL).

To assess OHRQoL, several instruments have been developed over the last decades [3]. One of the most commonly used instruments, based on the conceptual oral health model developed by Locker [4], is the Oral Health Impact Profile (OHIP) [5]. The original English version of this instrument consists of 49 items representing 7 conceptual domains (functional limitation, physical pain, psychological discomfort, physical disability, psychological disability, social disability and handicap). Several studies have demonstrated that this instrument has good psychometric properties (reliability and validity) with a reasonable degree of cross-cultural consistency [6-10]. To decrease the time needed for completion of the instrument, a short version was developed consisting of 14 items (OHIP-14). In spite of the limited number of items the short version of the OHIP has been proven to be also a valid and reliable instrument [11]. To be able to use OHIP-14 in non-English-speaking populations, this instrument has been translated and cross-culturally validated for several languages [12-17], but not yet for the Vietnamese language. The aim of this study was to 
translate a Vietnamese short version of the OHIP (OHIP$14 \mathrm{VN}$ ) and to validate it.

\section{MATERIAL AND METHODS}

\subsection{Translation Procedure}

In the translation process, the international guidelines for cross-cultural adaptation proposed by Guillemin et al. were applied with minor modifications however without stretching the principles of these guidelines [18]. The original version of the OHIP-14 was forward translated into the Vietnamese language by a dental professional (TCN), a practicing dentist and lecturer at the Faculty of Dentistry, Cantho University of Medicine and Pharmacy, Vietnam, with Vietnamese as native language and proficient in English. This forward translation and the original English version (source) were debated in a panel of a bilingual layperson and two bilingual doctors in medicine, specialized in epidemiology and the translation was revised according to their comments. This revised Vietnamese version was discussed in a committee of ten laypersons and one dentist. They were asked to give their comments regarding the quality of the translation and to assess it for clarity (use of simple and understandable expressions) and common language use. During the process of translation and revisions it was taken care that the conceptual context of the original version was maintained. After final revisions, a professional translator who had never seen the original English version, back-translated the Vietnamese forward translation. Comparison by two independent bilingual dentists of the original OHIP version (source) and the back-translated English version did not reveal conceptual content differences. In a pre-test the final version was presented to 30 laypersons. As this version appeared to be comprehensible no further revisions were made. The developed OHIP-14VN is available on request.

\subsection{Participants and Study Design}

For the validation process two random samples from subjects selected to participate in an epidemiological oral health study conducted in Southern Vietnam were drawn: the Study sample and the Test-retest sample (Table 1) [19].

Subjects were asked to self-administer a questionnaire. In case subjects were illiterate, could not read because of visual impairment, or needed help for any other reason, a dental assistant read aloud the questionnaire including the possible answers and recorded the answers chosen by the subjects. The administration format (self-administered vs. administered with assistance) was recorded to be able to analyze the possible effect of the administration format on the outcomes. Beside the OHIP-14VN, the questionnaire consisted of questions concerning gen- eral satisfaction with the dentition (no/yes), satisfaction with chewing function (no/yes), and satisfaction with esthetics (no/yes).

Concerning the OHIP-14VN, subjects were asked how frequently they had experienced an impact in the past 6 months. The format of the questions was "In the past 6 months, have you had .... because of problems with your teeth, mouth or dentures?" Responses were given on a five-point ordinal rating scale: $0=$ never; $1=$ hardly ever; 2 = occasionally; 3 = fairly often; $4=$ very often. After completion, the questionnaire was checked for unrecorded items and if applicable subjects were requested to complete the form.

Next, subjects underwent an oral examination. The examiner (TCN) was calibrated against three experienced researchers (AEG, DJW, NHJC) for assessment of DMFT. Following WHO criteria [20] a tooth was considered "decayed" if primary caries was detected, if the tooth was fractured, or if the tooth was filled but showed secondary caries. Caries was assessed by visual inspection, with additional tactile inspection with a dental probe if required. Only cavitated lesions with softened surfaces were recorded as caries. In case of doubt, no caries was recorded. A tooth root was recorded as "decayed" and a tooth was recorded as "missing" if the tooth was clinically absent. During the oral examination subjects were seated in an ordinary chair while daylight was used or a headlight when the natural light was felt to be insufficient.

The research was carried out in compliance with the Helsinki Declaration. The Educational Scientific Committee of Cantho University of Medicine \& Pharmacy granted ethics approval for this study (Decision No: 390/Q Đ.ĐHYDCT).

\subsection{Validity (Convergent and Groups)}

Validity of OHIP-14VN was tested in the Study sample (Table 1). Convergent validity was assessed calculating mean differences in OHIP scores of subjects reporting whether they were satisfied or not on three aspects of oral function (general satisfaction, chewing function and

Table 1. Demographic backgrounds of the Study sample and the Test-retest sample.

\begin{tabular}{cccc}
\hline & & $\begin{array}{c}\text { Study sample } \\
\mathrm{n}=724\end{array}$ & $\begin{array}{c}\text { Test-retest sample } \\
\mathrm{n}=54^{\mathrm{a}}\end{array}$ \\
\hline Mean age (SD) & & $46.6(15.4)$ & $43.6(12.2)$ \\
Gender (\%) & female & $370(51.1)$ & $23(42.6)$ \\
& male & $353(48.8)$ & $31(57.4)$ \\
Location (\%) & rural & $368(50.8)$ & $25(46.3)$ \\
& urban & $356(49.2)$ & $29(53.7)$ \\
\hline
\end{tabular}

${ }^{\mathrm{a}}$ Initial sample $(\mathrm{n}=60)$ minus 6 excluded subjects. 
esthetics): "Are you satisfied with your dentition in general/your dental esthetics/your chewing function?"; possible answers: "yes" or "no". Groups validity was evaluated by comparing mean OHIP scores with two dichotomized oral conditions: 1) presence of molars (including third molars): " $\leq 6$ molars vs. $>6$ molars", and 2) "having decay": one or more decayed teeth vs. no decayed teeth. It was hypothesized that subjects who were not satisfied (general satisfaction with dentition, chewing function or esthetics) had higher OHIP domain and total scores compared to their counterparts. Additionally, it was hypothesized that subjects having 6 or fewer molars present and subjects having one or more decayed teeth also had higher OHIP domain and total scores. Mean differences of OHIP domain and total scores were calculated and compared using t-tests. Significance level was set at $\alpha<$ 0.05 . Z-scores were calculated to express the size of the effects.

\subsection{Reliability}

Internal consistency was investigated in the Study sample by calculating Cronbach's alphas and average interitem correlation coefficients. Test-retest reliability was investigated in the Test-retest sample using a time interval of 3 weeks, and expressed in Intraclass Correlation Coefficients (ICCs) [21]. Because of recourse restraints and the burden for the participants the Test-retest sample was kept as small as possible and a number of 60 subjects was estimated to be sufficient to investigate the testretest reliability. It appeared that 6 subjects experienced toothache, illness, or a life event like death of a family member during the 3 weeks time interval. They were excluded from the Test-retest sample. As a result the final Test-retest sample comprised 54 subjects (Table 1).

\section{RESULTS}

\subsection{Validity (Convergent and Groups)}

Overall mean OHIP domain and total scores were higher, as hypothesized, for subjects not satisfied with their dentition in general, not satisfied with chewing function, and not satisfied with the esthetic appearance of their dentition compared to their counterparts. Having $\leq 6$ molars present was also, as expected, associated with higher OHIP total and domain scores and again all mean differences were statistically significant except for the domain "handicap" $(p=0.24)$. In contrast, mean differences for having one or more decayed teeth or not were not significant except for the domains "functional limitation" and "psychological discomfort" (Figure 1).

With respect to the administration format, for those who received assistance the OHIP-VN total scores and four out of seven domain scores were statistically significant lower than the scores for subject who self-administered the questionnaire (Table 2). Therefore further analyses were performed separately for the two administration formats. For both administration formats the differences in mean scores were statistically significant different for "general satisfaction", "satisfaction with chewing" and "satisfaction with esthetics" (Table 3). The expected differences were also found for the variable "presence of $\leq 6$ vs.

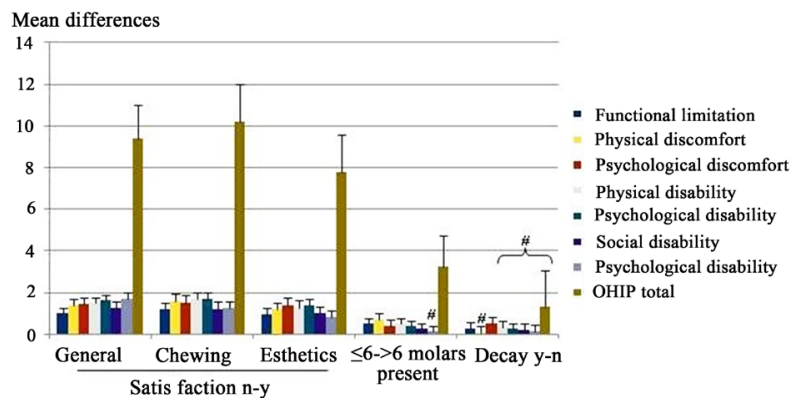

Figure 1. Convergent and groups validity (Study sample; $\mathrm{n}=$ 724). Differences in mean OHIP domain and total scores in relation to satisfaction of subjects on oral function and two dichotomized oral conditions. Error bars indicate $2 \times$ SE. All differences significantly different $(p<0.05)$ except those indicated by \#.

Table 2. Overall mean OHIP scores (SD) (Study sample; $\mathrm{n}=$ 724), mean OHIP scores (SD) by administration format $(\mathrm{N}=$ self-administered $(\mathrm{n}=217) ; \mathrm{Y}=$ received assistance $(\mathrm{n}=507))$ and p-values of two tailed t-tests for equality of means for domain and total scores.

\begin{tabular}{|c|c|c|c|c|}
\hline \multicolumn{5}{|c|}{ Overall } \\
\hline OHIP domain & Mean score (SD) & Assistance & Mean score & $\mathrm{p}$ value \\
\hline \multirow{2}{*}{$\begin{array}{l}\text { Functional } \\
\text { limitation }\end{array}$} & \multirow{2}{*}{$1.07(1.54)$} & $\mathrm{N}$ & $1.22(1.52)$ & \multirow{2}{*}{0.215} \\
\hline & & $\mathrm{Y}$ & $1.01(1.54)$ & \\
\hline \multirow{2}{*}{$\begin{array}{l}\text { Physical } \\
\text { discomfort }\end{array}$} & \multirow{2}{*}{$1.98(1.96)$} & $\mathrm{N}$ & $2.05(2.02)$ & \multirow{2}{*}{0.065} \\
\hline & & Y & 1.95 (1.94) & \\
\hline \multirow{2}{*}{$\begin{array}{l}\text { Psychological } \\
\text { discomfort }\end{array}$} & \multirow{2}{*}{$1.28(1.92)$} & $\mathrm{N}$ & $1.63(2.05)$ & \multirow{2}{*}{0.013} \\
\hline & & $\mathrm{Y}$ & $1.13(1.86)$ & \\
\hline \multirow{2}{*}{$\begin{array}{l}\text { Physical } \\
\text { disability }\end{array}$} & \multirow{2}{*}{$1.43(1.89)$} & $\mathrm{N}$ & 1.57 (1.94) & \multirow{2}{*}{0.683} \\
\hline & & $\mathrm{Y}$ & $1.37(1.87)$ & \\
\hline \multirow{2}{*}{$\begin{array}{l}\text { Psychological } \\
\text { disability }\end{array}$} & \multirow{2}{*}{$1.17(1.82)$} & $\mathrm{N}$ & $1.55(1.91)$ & \multirow{2}{*}{0.002} \\
\hline & & Y & $1.01(1.76)$ & \\
\hline \multirow{2}{*}{$\begin{array}{c}\text { Social } \\
\text { disability }\end{array}$} & \multirow{2}{*}{$0.97(1.65)$} & $\mathrm{N}$ & $1.38(1.78)$ & \multirow{2}{*}{$<0.001$} \\
\hline & & $\mathrm{Y}$ & $0.80(1.57)$ & \\
\hline \multirow{2}{*}{ Handicap } & \multirow{2}{*}{$0.93(1.54)$} & $\mathrm{N}$ & $1.24(1.73)$ & \multirow{2}{*}{$<0.001$} \\
\hline & & Y & $0.79(1.43)$ & \\
\hline \multirow{2}{*}{ OHIP total } & \multirow{2}{*}{$9.52(9.90)$} & $\mathrm{N}$ & $11.05(10.42$ & \multirow{2}{*}{0.022} \\
\hline & & Y & $8.87(9.60)$ & \\
\hline
\end{tabular}




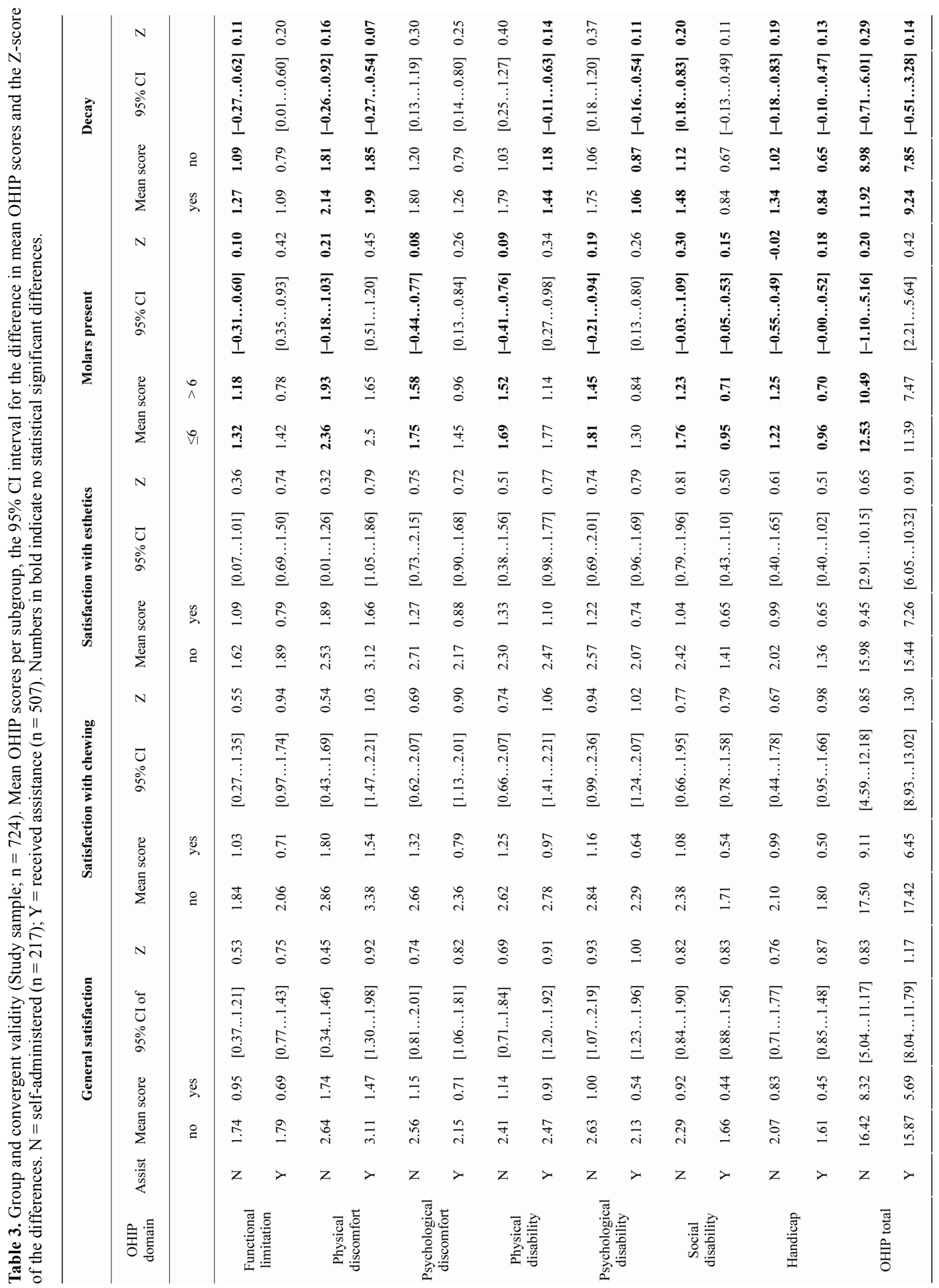


$>6$ molars", however, for the group who had no assistance differences for all domains scores and OHIP total score were not statistically significant. For the group who had assistance the differences were significant except for the domains "social disability" and "handicap". For the variable "having decay" (yes/no) the differences in mean scores were also in the expected direction, however for both administration format only three out of seven domains revealed significant differences, and the differences in mean OHIP total scores were not statistically significant. Effect size (Table 3) was smallest for the variable "presence of $\leq 6$ or $>6$ molars" and the variable "having decay" (yes/no) (Z-scores ranging from -0.02 to $0.45)$ and largest for "satisfaction with chewing" (Z-scores ranging from 0.54 to 1.30 ) followed by "general satisfaction" (Z-scores ranging from 0.45 to 1.17 ) and "satisfaction with esthetics" (Z-scores ranging from 0.32 to 0.91 ).

\subsection{Reliability}

The mean differences for the test-retest scores and the test-retest reliability expressed in ICC for the seven domains and OHIP-14VN total scores are presented in Table 4. ICCs ranged from 0.54 to 0.65 for the domain scores with an ICC of 0.74 for the total score. According to Fleiss this reflects fair to good test-retest reliability [22]. Internal consistency of the domain scores expressed in Cronbach's alphas (Table 5) ranged from 0.41 to 0.81 for the subjects who self-administered the questionnaire and 0.43 to 0.82 for the subjects who had assistance. Cronbach's alphas for OHIP total scores were 0.93 and 0.91 respectively. This indicates modest internal consistency for domain scores and good consistency for total scores [23]. Average inter-item correlations ranged from 0.26 to 0.67 for the group who self-administered the questionnaire and from 0.28 to 0.69 for the group who had assistance. These outcomes were mostly within the desirable range of 0.40 to 0.50 for scales tapping narrow characteristics [24].

\section{DISCUSSION}

To investigate the feasibility for use in future large-scale epidemiological studies including large numbers of questions on several topics, OHIP-14 was decided on. The use of OHIP-49 was considered to be a too extensive fieldwork effort to the researcher and would place an undesirable burden on the respondents.

Table 4. Test-retest reliability (Test-retest sample; $n=54)$. Intra-class correlation coefficients (ICCs) for the OHIP domain and total scores.

\begin{tabular}{cccc}
\hline OHIP domain & $\begin{array}{c}\text { Mean difference } \\
\text { test-retest scores }\end{array}$ & $95 \%$ CI & ICC \\
\hline Functional limitation & -0.43 & {$[-0.79 \ldots-0.60]$} & 0.59 \\
Physical discomfort & -0.67 & {$[-1.19 \ldots-0.14]$} & 0.54 \\
Psychological discomfort & -0.24 & {$[-0.66 \ldots 0.18]$} & 0.58 \\
Physical disability & -0.22 & {$[-0.55 \ldots 0.11]$} & 0.63 \\
Psychological disability & -0.19 & {$[-0.52 \ldots 0.15]$} & 0.65 \\
Social disability & -0.06 & {$[-0.43 \ldots 0.32]$} & 0.62 \\
Handicap & -0.30 & {$[-0.63 \ldots 0.04]$} & 0.58 \\
OHIP total & -1.32 & {$[-2.91 \ldots 0.28]$} & 0.74 \\
\hline
\end{tabular}

Table 5. Internal consistency (Study sample; $\mathrm{n}=724$ ). Cronbach's alphas and average inter-item correlations by administration format.

\begin{tabular}{|c|c|c|c|c|}
\hline \multirow[b]{2}{*}{ OHIP domain } & \multicolumn{2}{|c|}{ Cronbach's alpha } & \multicolumn{2}{|c|}{ Average inter-item correlation } \\
\hline & Self-administered & With assistance & Self-administered & With assistance \\
\hline Functional limitation & 0.41 & 0.45 & 0.26 & 0.33 \\
\hline Physical discomfort & 0.66 & 0.43 & 0.50 & 0.28 \\
\hline Psychological discomfort & 0.78 & 0.74 & 0.64 & 0.59 \\
\hline Physical disability & 0.75 & 0.60 & 0.61 & 0.43 \\
\hline Psychological disability & 0.81 & 0.82 & 0.67 & 0.69 \\
\hline Social disability & 0.79 & 0.73 & 0.65 & 0.58 \\
\hline Handicap & 0.66 & 0.59 & 0.49 & 0.42 \\
\hline OHIP total & 0.93 & 0.91 & & \\
\hline
\end{tabular}


In the translation process, principles of the international guidelines for cross-cultural adaptation recommended by Guillemin [18] et al. were followed, however with minor modifications for practical reasons, being a limited availability of bi-lingual people and financial restrains. A bilingual dentist familiar to the concept of OHIP instead of a professional translator produced the forward translation. On the one hand, an advantage of using a bi-lingual dental researcher as the forward translator is that it ensures maintenance of the conceptual context of the original version. On the other hand, lack of several translations as proposed by the guidelines might influence the quality of the translation. To compensate for this a panel of a bilingual layperson and two bilingual doctors in medicine, specialized in epidemiology compared the translation with the original version and discussed alternative translations. The cultural representativeness of this forward translation was guarded by independent assessment in the pre-test by a group of laypersons. In spite of these minor modifications, the process resulted in a Vietnamese version of OHIP-14 that, after the validation process, appeared to show acceptable psychometric properties.

Unexpectedly, $63 \%$ of the subjects in this study asked for assistance to complete the questionnaires and for these subjects the questionnaires were read aloud by a dental assistant. This percentage is substantially higher than the official percentage of illiterates. According to the General Statistic Office of Vietnam 7\% of the population of 10 years and older are illiterate [25]. A possible explanation for this is that those who asked for assistance also include subjects who are functional illiterate as well as subjects with visual impairment.

Mean OHIP domain scores as well as the total score were lower for subjects who received assistance and these differences was statistically significant for 4 domains scores as well as the OHIP total score and were also present after adjusting for age and SES, suggesting that the results were indeed effected by administration format. Likewise, applying the threshold of clinically meaningful difference of 0.2 times the standard deviation, as suggested by Puhan et al. (2011), the same domains showed a difference for administration format above this threshold [26]. Possibly the phenomenon of so-called social desirability [27] has biased the results of the present study. Our finding in this respect is in contrast to recent studies in Malaysia, the UK and USA [17,28], which showed no relationship between the psychometric properties of the respective OHIP-14s and the questionnaire format. Although alternate administration formats caused some significant differences in OHIP outcome, the administration format sec seemed not to have affected the general trend in the relationships reported. However, this effect of administration format should be taken into account when analyzing OHIP data in future research in
Vietnam. Moreover, as this finding was more or less by chance and not anticipated for in the study design it would be worthwhile to further explore this phenomenon in a study especially designed for this purpose [26].

All differences in OHIP-14VN scores for satisfaction and oral conditions were in the expected direction. However when considering administration format the association with the oral condition having $\leq 6$ molars lost significance for most domains and OHIP-14VN total, especially for the group who self-administered the questionnaire. Associations with "having decay" (yes/no) were even weaker and not statistically significant for OHIP-14VN total scores for both administration formats. These findings might be due to the chosen cut-off points. Other cutoff points could have been more discriminative, but would not be statistically sound, as they would have caused too skewed distributions of caries and missing molars amongst the groups [19].

Test-retest reliability was relatively low compared to other OHIP-14 validation studies [12-14,16]. A possible explanation for the relatively low ICCs is the low level of deviation in the overall OHIP scores, indicating high homogeneity of the responses. High homogeneity of the responses will result in lower ICCs and this is independent of test-retest reliability of the instrument used. Never- theless, according to Fleiss' interpretation, ICC values above 0.40 and below 0.75 , as in the present study, indicate fair to good test-retest reliability [21].

In this study, all mean differences in OHIP scores for the dichotomized conditions were in the expected direction. The relations with satisfaction were significant for both OHIP domain and total scores. The relation with the oral condition "presence of $\leq 6$ vs. $>6$ molars" was significant, but lost significance after taking the administration format into account for many domains and OHIP total, especially for the format self-administered. The relationships "having decay" (yes/no) was even weaker and not statistically significant for OHIP total score for both formats. The test-retest reliability is considered fair to good.

\section{CONCLUSIONS}

This Vietnamese version of the Oral Health Impact Profile (OHIP-14VN) demonstrated fair to good construct validity and reliability for OHIP total score and can be considered a valid and reliable instrument to assess the prevalence of impacts on OHRQoL in large-scale epidemiological studies in Vietnam. However, OHIP-14VN domain scores should be interpreted with caution.

Administration format remains an issue to be considered in epidemiological studies in Vietnam.

\section{REFERENCES}

[1] Allen, P.F. (2003) Assessment of oral health related qual- 
ity of life. Health and Quality of Life Outcomes, 1, 40. http://www.hqlo.com/content/1/1/40

[2] Locker, D. and Allen, P.F. (2007) What do measures of "oral health-related quality of life" measure? Community Dentistry Oral Epidemiology, 35, 401-411. doi:10.1111/j.1600-0528.2007.00418.x

[3] Brondani, M.A. and MacEntee, M.I. (2007) The concept of validity in sociodental indicators and oral health-related quality-of-life measures. Community Dentistry Oral Epidemiology, 35, 472-478. doi:10.1111/j.1600-0528.2006.00361.x

[4] Locker, D. (1988) Measuring oral health: A conceptual framework. Community Dentistry Oral Epidemiology, 5, 3-18.

[5] Slade, G.D. and Spencer, A.J. (1994) Development and evaluation of the oral health impact profile. Community Dental Health, 11, 3-11.

[6] John, M.T., Patrick, D.L. and Slade, G.D. (2002) The German version of the oral health impact profileTranslation and psychometric properties. European Journal of Oral Sciences, 110, 425-433. doi:10.1034/j.1600-0722.2002.21363.x

[7] Larsson, P., List, T., Lundstrom, I., Marcusson, A. and Ohrbach, R. (2004) Reliability and validity of a Swedish version of the oral health impact profile (OHIP-S). Acta Odontologica Scandinavia, 62, 147-152. doi:10.1080/00016350410001496

[8] Pires, C.P., Ferraz, M.B. and de Abreu, M.H. (2006) Translation into Brazilian Portuguese, cultural adaptation and validation of the oral health impact profile (OHIP-49). Brazilian Oral Research, 20, 263-268. doi:10.1590/S1806-83242006000300015

[9] van der Meulen, M.J., John, M.T., Naeije, M. and Lobbezoo, F. (2008) The Dutch version of the oral health impact profile (OHIP-NL): Translation, reliability and construct validity. BMC Oral Health, 8, 11 . doi:10.1186/1472-6831-8-11

[10] Wong, M.C., Lo, E.C. and McMillan, A.S. (2002) Validation of a Chinese version of the oral health impact profile (OHIP). Community Dentistry Oral Epidemiology, 30, 423-430. doi:10.1034/j.1600-0528.2002.00013.x

[11] Slade, G.D. (1997) Derivation and validation of a shortform oral health impact profile. Community Dentistry Oral Epidemiology, 25, 284-290. doi:10.1111/j.1600-0528.1997.tb00941.x

[12] Ravaghi, V., Farrahi-Avval, N., Locker, D. and Underwood, M. (2010) Validation of the Persian short version of the oral health impact profile (OHIP-14). Oral Health \& Preventive Dentistry, 8, 229-235.

[13] Fernandes, M.J., Ruta, D.A., Ogden, G.R., Pitts, N.B. and Ogston, S.A. (2006) Assessing oral health-related quality of life in general dental practice in Scotland: Validation of the OHIP-14. Community Dentistry Oral Epidemiology, 34, 53-62. doi:10.1111/j.1600-0528.2006.00254.x

[14] John, M.T., Miglioretti, D.L., LeResche, L., Koepsell, T.D., Hujoel, P. and Micheelis, W. (2006) German short forms of the oral health impact profile. Community Den- tistry Oral Epidemiology, 34, 277-288. doi:10.1111/j.1600-0528.2006.00279.x

[15] Kushnir, D., Zusman, S.P. and Robinson, P.G. (2004) Validation of a Hebrew version of the oral health impact profile 14. Journal of Public Health Dentistry, 64, 71-75. doi:10.1111/j.1752-7325.2004.tb02730.x

[16] Rener-Sitar, K., Petricevic, N., Celebic, A. and Marion, L. (2008) Psychometric properties of Croatian and Slovenian short form of oral health impact profile questionnaires. Croatian Medical Journal, 49, 536-544. doi:10.3325/cmj.2008.4.536

[17] Saub, R., Locker, D. and Allison, P. (2005) Derivation and validation of the short version of the Malaysian oral health impact profile. Community Dentistry Oral Epidemiology, 33, 378-383. doi:10.1111/j.1600-0528.2005.00242.x

[18] Guillemin, F., Bombardier, C. and Beaton, D. (1993) Cross-cultural adaptation of health-related quality of life measures: Literature review and proposed guidelines. Journal of Clinical Epidemiology, 46, 1417-1432. doi:10.1016/0895-4356(93)90142-N

[19] Nguyen T.C., Witter D.J., Bronkhorst E.M., Truong N.B. and Creugers N.H.J. (2010) Oral health status of adults in Southern Vietnam-A cross-sectional epidemiological study. BMC Oral Health, 10, 2. doi:10.1186/1472-6831-10-2

[20] World Health Organization. (1997) Indices and methods for measurement of dental diseases, WHO oral health surveys.

http://www.whocollab.od.mah.se/expl/methods.html

[21] Bartko, J.J. (1966) The intraclass correlation coefficient as a measure of reliability. Psychological Reports, 19, 3-11. doi:10.2466/pr0.1966.19.1.3

[22] Fleiss, J.L. (1986) The design and analysis of clinical experiments. John Wiley \& Sons, New York.

[23] Bland, J.M. and Altman, D.G. (1997) Cronbach's alpha. British Medical Journal, 314, 572. doi:10.1136/bmj.314.7080.572

[24] Clark, L.A. and Watson, D. (1995) Constructing validity: Basic issues in objective scale development. Psychological Assessment, 7, 309-319. doi:10.1037/1040-3590.7.3.309

[25] General Statistics Office of Vietnam. http://www.gso.gov.vn/default en.aspx?tabid=483\&idmi $\mathrm{d}=4 \&$ ItemID $=4343$

[26] Puhan, M.A., Ahuja, A., Van Natta, M.L., Ackatz, L.E. and Meinert, C. (2011) Interviewer versus self-administered health-related quality of life questionnaires - Does it matter? Health and Quality of Life Outcomes, 9, 30. doi:10.1186/1477-7525-9-30

[27] Bowling, A. (2005) Mode of questionnaire administration can have serious effects on data quality, Journal of Public Health (Oxf), 27, 281-291. doi:10.1093/pubmed/fdi031

[28] Robinson, P.G., Gibson, B., Khan, F.A. and Birnbaum, W. (2001) A comparison of OHIP 14 and OIDP as interviews and questionnaires. Community Dental Health, 18, 144149. 


\section{Abbreviations}

ICC: Intraclass Correlation Coefficients

OHIP: Oral Health Impact Profile

OHIP-14VN: Vietnamese version of the 14 item OHIP

OHRQoL: Oral Health Related Quality of Life 